\title{
Desain Tata Kelola Sampah Menuju Smart City Menggunakan Paradigma Model Prototype Berbasis Green Technology
}

\author{
N. Tri Suswanto Saptadi ${ }^{1}$, Ferdinandus Sampe ${ }^{2}$, Phie Chyan ${ }^{3}$ \\ ${ }^{1,3}$ Jurusan Teknik Informatika Fakultas Teknologi Informasi Universitas Atma Jaya Makassar \\ ${ }^{2}$ Jurusan Manajemen Fakultas Ekonomi dan Bisnis Universitas Atma Jaya Makassar \\ E-mail: 1ntsaptadi@yahoo.com, ㄹerdisampe@yahoo.com, ${ }^{3}$ phie_chyan@ lecturer.uajm.ac.id
}

\begin{abstract}
Abstrak
Era disrupsi telah mampu merubah paradigma pemerintah terhadap kontribusi Teknologi Informasi (TI). Tata kelola yang baik dapat memberikan layanan informasi yang cepat, relevan dan akurat kepada masyarakat. Tren Tata kelola kota cerdas juga akan meningkatkan partisipasi masyarakat dan pemerintah dalam memanfaatkan data aplikasi, memberikan saran maupun kritikan secara cepat, mudah dan akurat. Kota Makassar telah mencanangkan program menuju kota yang bersih lingkungan. Pemerintah kota (Pemkot) telah melakukan inovasi dalam menangani masalah kebersihan dengan berusaha merekonstruksi pemikiran masyarakat untuk cinta dan peduli terhadap kebersihan. Meskipun demikian masih banyak masyarakat yang belum tahu apa sebenarnya yang dimaksud dengan Gemar MTR dan bagaimana konsep tersebut dapat diterapkan. Pemerintah perlu selalu aktif dalam mengupayakan kebersihan lingkungan sehingga dapat membantu merubah pola pikir masyarakat terhadap kebersihan lingkungan. Penelitian bertujuan untuk mengetahui penerapan konsep tata kelola sampah menuju kota pintar di Makassar, dan mendesain tata kelola sampah agar dapat memenuhi kebutuhan dan harapan pemerintah dan masyarakat. Penelitian menggunakan paradigma model prototipe untuk mendesain tata kelola berbasis teknologi hijau. Tata kelola baik berguna untuk memelihara lingkungan hidup secara terintegrasi sehingga akan memberikan solusi ramah lingkungan, optimalisasi desain dan arsitektur TIK yang berdampak positif pada lingkungan masyarakat kota.
\end{abstract}

Kata Kunci_tata kelola, kota cerdas, desain, prototipe

\begin{abstract}
The era of disruption has been able to change the paradigm of government towards the contribution of Information Technology (IT). Good governance can provide fast, accurate and relevant information services to the public. Trends in smart city governance will also increase public and government participation in utilizing application data, providing suggestions and criticisms quickly, easily and accurately. Makassar City has launched a program towards an environmentally clean city. The city government has innovated in dealing with hygiene issues by trying to reconstruct people's thinking to love and care for cleanliness. Nevertheless there are still many people who do not know what exactly is meant by Gemar MTR and how the concept can be applied. The government needs to be active in pursuing environmental cleanliness so that it can help change people's mindset towards environmental cleanliness. The study aims to determine the application of the concept of waste management to smart cities in Makassar, and design waste management in order to meet the needs and expectations of the government and the community. Research uses a prototype model paradigm to design green technology-based governance. Good governance is useful for maintaining the environment in an integrated manner so that it will provide environmentally friendly solutions, optimization of ICT designs and architecture that have a positive impact on the city's urban environment.
\end{abstract}

Keywords-governance, smart city, design, protopype

\section{Pendahuluan}

Era disrupsi telah mampu merubah paradigma pemerintah dalam meningkatkan pelayanan melalui kontribusi Teknologi Informasi (TI). Tata kelola yang baik dapat memberikan layanan informasi yang cepat, tepat dan akurat kepada masyarakat. Penelitian dilaksanakan berdasarkan fenomena di era disrupsi 
yang telah mampu merubah paradigma pemerintah terhadap pelayanan informasi yang cepat, tepat, akurat dan baik kepada masyarakat yang membutuhkan layanan informasi menuju tata kelola smart city. Gerakan menuju 100 Smart City merupakan program bersama Kementerian Komunikasi dan Informasi, Kementerian Dalam Negeri, Kementerian PUPR, Bappenas dan Kantor Staf Kepresidenan. Gerakan tersebut bertujuan untuk membimbing Kabupaten/Kota dalam menyusun Masterplan Smart City agar bisa lebih memaksimalkan pemanfaatan teknologi, baik dalam meningkatkan pelayanan masyarakat maupun mengakselerasikan potensi yang ada di masing-masing daerah [1].

Dimensi terpenting dari smart city adalah bahwa kota saat ini seharusnya memberikan pelayanan yang menggunakan teknologi terkini dan membangun infrastruktur yang pintar, sehingga dapat memberikan pelayanan yang efektif dan murah kepada seluruh masyarakat yang tinggal di kota. Sejalan dengan pengembangan smart city di Indonesia yang disampaikan oleh Direktur Perkotaan dan Perdesaan Kementerian PPN/Bappenas dalam acara Konferensi e-Indonesia Initiative (eII) dan Smart Indonesia Initiatives (SII) Forum ke-1 di Bandung, 15 Oktober 2015, urbanisasi tengah terjadi dari desa ke kota dari tahun ke tahun yang menunjukkan angka cukup signifikan. Salah satu misi dalam sasaran pembangunan kota berkelanjutan 2015-2045 adalah membangun kegiatan perekonomian dan masyarakat kota berdaya saing yang produktif, kreatif dan inovatif, efisien serta berbasis TI melalui pendekatan tata kelola [2].

Kota Makassar mencanangkan program menuju kota yang bersih. Pemerintah kota (Pemkot) telah melakukan inovasi dalam menangani masalah kebersihan dengan mencoba merekonstruksi pemikiran masyarakat untuk cinta dan peduli terhadap kebersihan. Untuk merealisasikan pemkot membuat program Gerakan Makassar Ta tidak Rantasa (Gemar MTR) yang bertujuan untuk merubah pola pikir masyarakat agar cinta bersih dan selalu hidup sehat [3]. Dalam menjalankan program tersebut, Walikota Makassar telah membuat Surat Keputusan berupa instruksi kepada SKPD dan Kecamatan se-kota Makassar utamanya Dinas kebersihan agar melaksanakan program yang mendukung MTR. Dibutuhkan tata kelola sampah yang baik menggunakan TI dengan metode rekayasa perangkat lunak model prototype agar dapat menciptakan budaya kehidupan menuju smart city melalui program tersebut [4].

Dalam perkembangan tersebut masih banyak masyarakat yang belum tahu, apa sebenarnya yang dimaksud dengan Gemar MTR dan bagaimana konsep pelaksanaannya. Dalam pandangan tersebut keberadaan program yang tidak memiliki dasar kebijakan yang tidak jelas, dikhawatirkan tidak akan terealisasi dengan maksimal karena ada proses yang tidak berkesinambingan dalam perumusan program dengan memanfaatkan TI. Permasalahan dalam penelitian dapat dirumuskan, sebagai berikut: bagaimana penerapan konsep tata kelola sampah menuju smart city di Kota Makassar, dan bagaimana desain tata kelola sampah menggunakan metode prototype. Tujuan yang akan dicapai dalam desain tata kelola, yaitu: tercapainya penerapan konsep tata kelola smart city di Makassar, dan menghasilkan suatu desain tata kelola sampah menggunakan paradigma model prototype berbasis green technology (greentech).

\section{Metode Penelitian}

IT Governance atau Tata Kelola TI (TKTI) adalah upaya menjamin pengelolaan TI agar mendukung bahkan selaras dengan strategi bisnis suatu enterprise yang dilakukan oleh dewan direksi, manajemen eksekutif, dan juga oleh manajemen TI [5]. TKTI adalah suatu struktur hubungan dan proses untuk mengatur dan mengontrol perusahaan yang bertujuan untuk mencapai tujuan perusahaan yang telah ditetapkan dengan pertambahan nilai dengan tetap menyeimbangkan resiko dengan nilai yang didapatkan dari penerapan TI dan prosesnya [6].

\subsection{Standar TKTI}

Standar TKTI menggabungkan bidang pengelolaan institusi secara umum yang merupakan komponen pengelolaan institusi secara keseluruhan dan terintegrasi, dengan fokus tanggung jawab utama, yaitu: memastikan agar kepentingan stakeholders dapat diikutsertakan dalam penyusunan strategi institusi, memberikan arahan kepada proses yang menerapkan strategi institusi, memastikan proses tersebut menghasilkan keluaran yang terukur, memastikan adanya informasi mengenai hasil yang diperoleh dan mengukurnya, serta memastikan keluaran yang dihasilkan sesuai dengan yang diharapkan oleh stakeholders. TKTI merupakan konsep yang 
berkembang dari sektor swasta, namun dengan berkembangnya penggunaan TI oleh organisasi pemerintahan maka TKTI juga harus diterapkan di sektor ini [7]. Peranan TKTI dapat melakukan pencapaian tujuan suatu organisasi yang mengadopsi penggunaan TI sehingga kegiatan manajemen menghasilkan keluaran yang maksimal dalam organisasi, membantu proses pengambilan keputusan dan membantu proses pemecahan masalah [8].

\subsection{Smart City}

Definisi atau pengertian Smart City (kota pintar) sangat beraneka ragam. Konsep tersebut sudah dikenal dengan populer, namun dalam prakteknya digunakan di berbagai negara dengan istilah yang berbeda dan situasi yang berbeda pula. Ada penggunaan berbagai jenis konsep mengganti smart dengan istilah kata sifat lainnya. Smart city adalah visi pembangunan perkotaan untuk mengintegrasikan beberapa Information Computer of Technology (ICT) dan solusi Internet of Things (IOT) dalam sebuah bentuk yang aman untuk mengelola aset kota. Definisi dari smart city itu begitu luas sehingga mencakup berbagai macam keseluruhan teknologi digital yang dapat meningkatkan kualitas kehidupan, mengurangi biaya dan sumber konsumsi, serta dapat meningkatkan interaksi aktif antara kota dan warganya secara efektif [9].

Deakin mendefinisikan smart city sebagai salah satu yang memanfaatkan ICT untuk memenuhi tuntutan pasar (warga kota), dan bahwa keterlibatan masyarakat dalam proses ini diperlukan untuk sebuah kota pintar. Sehingga smart city akan menjadi kota yang tidak hanya memiliki teknologi ICT di daerah tertentu, tetapi juga telah menerapkan teknologi ini dengan cara yang positif berdampak pada masyarakat sekitar. Kota yang disebut smart city adalah kota yang memiliki terobosan baru dalam penyelesaian-penyelesaian masalah di kota, dan sukses meningkatkan performa kota [10]. Perkembangan konsep telah membawa pemahaman teknologi. Dalam penerapan tetap melihat aspek lain yang dibutuhkan oleh kota pada umumnya dengan aspek yang menyeluruh sehingga dapat disebut sebagai kota cerdas. Teknologi hijau (greentech) atau teknologi lingkungan (envirotech) dan teknologi bersih (cleantech) adalah integrasi antara teknologi modern dan ilmu lingkungan untuk lebih melestarikan lingkungan global dan sumber daya alam serta untuk mengurangi dampak negative dari aktifitas manusia di planet bumi. Greentech melakukan pengembangan dan penerapan produk, peralatan dan sistem yang digunakan untuk melestarikan lingkungan alam dan sumber daya, yang meminimalkan dan mengurangi dampak negatif dari aktivitas manusia terhadap lingkungan.

\subsection{Prototype}

Penelitian menggunakan pendekatan berdasarkan paradigma model prototype [11]. Model ini melakukan pengerjaan suatu sistem secara berurutan atau linear. Metode penelitian ini memiliki 5 langkah yaitu: Communication, Quick Plan, Modeling Quick Design, Construction of Prototype, dan Deployment Delivery and Feedback. Melalui model prototyping ini pengembang dan pengguna dapat saling berinteraksi selama proses pembuatan sistem. Perubahan terhadap desain dan sistem yang diharapkan bersama dapat dengan mudah diadopsi dan disesuaikan melalui kesepakatan. Secara spontan, pengguna dapat memberikan masukan atas hasil yang diperoleh dan tentu menjadi masukan bagi pengembang sistem. Kemudian pengembang berkewajiban membuat sistem berdasarkan masukan agar diperoleh hasil desain yang baik dan sesuai dengan kebutuhan pengguna. Sistem yang baik akan mengurangi risiko kesalahan dalam menangani transaksitransaksi yang jumlahnya banyak dan transaksi yang terjadi berulang-ulang [12]. Rekayasa perangkat lunak dimungkinkan untuk membuat berbagai aplikasi seperti pemetaan pengelolaan sampah, distribusi sampah kepada industri usaha kecil dan menengah (UKM), dan analisa dampak lingkungan untuk deteksi persebaran sampah di kota Makassar. 


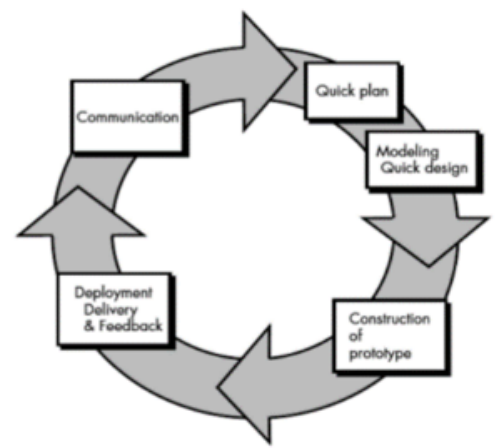

Gambar 1. Paradigma Model Prototype

Berikut penjelasan mengenai tahapan dalam model Prototype, yaitu:

\section{Communication}

Tahapan ini dilakukan dengan cara melakukan wawancara dan pengumpulan data yang berkaitan dengan kebutuhan desain model tata kelola sampah dengan berkomunikasi kepada dinas kebersihan, dinas komunikasi dan informasi, serta masyarakat pengguna layanan.

\section{Quick Plan}

Tahapan ini membuat perencanaan secara cepat dengan cara membuat agenda pertemuan, mendiskusikan materi, membuat langkah perencanaan, hingga pelaksanaan.

\section{Modeling Quick Design}

Tahapan ini membuat pemodelan perancangan secara cepat dengan cara desain model tata kelola sampah yang menjadi pedoman dalam menuju smart city. Untuk itu diperlukan dokumen pendukung dan keterkaitan dengan instansi terkait lain yang memiliki kewenangan dalam tata kelola sampah.

\section{Construction of Prototype}

Tahapan ini membentuk prototipe yang sesuai dengan harapan dan kebutuhan agar dapat menerapkan konsep tata kelola menuju smart city.

\section{Deployment Delivery and Feedback}

Tahapan ini dilakukan dengan cara menyerahkan model tata kelola sampah kepada pengguna untuk kemudian melalukan pengiriman dan menerima umpan balik.

\section{Hasil dan Pembahasan}

Pengumpulan data dilakukan melalui tahapan kuesioner dengan menggunakan aplikasi google form. Data yang diperoleh dari responden berjumlah 120 orang yang berdomisili di Makassar dan berasal dari 14 kecamatan, yaitu: Biringkanaya, Bontoala, Makassar, Mamajang, Manggala, Mariso, Panakukkang, Rappocini, Tallo, Tamalanrea, Tamalate, Ujung Pandang, Ujung Tanah, dan Wajo.

\subsection{Demografi Responden}

Demografi responden ditentukan dengan kebutuhan data yang terdiri dari jenis kelamin, umur, pendidikan, dan domisili.

1. Jenis Kelamin

Responden dalam pengisian kuesioner memiliki jenis kelamin berbeda dengan jumlah responden 120 orang. Berdasarkan jenis kelamin terdapat $65 \%$ laki-laki dan 35\% perempuan.

Tabel 1. Responden berdasarkan Jenis Kelamin

\begin{tabular}{lll}
\hline Jenis Kelamin & Jumlah & Persentase \\
\hline
\end{tabular}


2. Umur

\begin{tabular}{lll}
\hline Laki-laki & 78 & 65 \\
Perempuan & 42 & 35 \\
\hline Total & 120 & 100 \\
\hline
\end{tabular}

Sumber: Data Diolah, 2018

Responden dalam pengisian kuesioner memiliki umur cukup beragam. Berdasarkan umur terdapat $80 \%$ (17-25), $9 \%$ (11-9), $8 \%$ (26-35), dan 3\% (46-55).

Tabel 2. Responden berdasarkan Umur

\begin{tabular}{llll}
\hline Rentang & $\begin{array}{l}\text { Tahun } \\
\text { Lahir }\end{array}$ & Jumlah & Persentase \\
\hline $17-25$ & $1993-2001$ & 96 & 80 \\
$26-35$ & $1983-1992$ & 9 & 8 \\
$36-45$ & $1973-1982$ & 11 & 9 \\
$46-55$ & $1963-1972$ & 4 & 3 \\
\hline \multicolumn{5}{c}{ Total } & 120 & 100 \\
\hline
\end{tabular}

Sumber: Data Diolah, 2018

\section{Pendidikan}

Responden pengisian kuesioner berasal dari jenjang strata pendidikan yang berbeda. Berdasarkan pendidikan terdapat 30,8\% (S1), 11,7\% (S2), 1,7\% (S3), dan 1,7\% (lainnya).

Tabel 3. Pendidikan Responden

\begin{tabular}{lll}
\hline Strata & Jumlah & Persentase \\
SMU/SMK & 65 & 54,2 \\
\hline S1 & 37 & 30,8 \\
S2 & 14 & 11,7 \\
S3 & 2 & 1,7 \\
Lainnya & 2 & 1,7 \\
\hline Total & 120 & 100 \\
\hline Sumber:
\end{tabular}

4. Domisili Kecamatan

Tabel berikut menunjukkan domisili responden berdasarkan 14 kecamatan di kota Makassar.

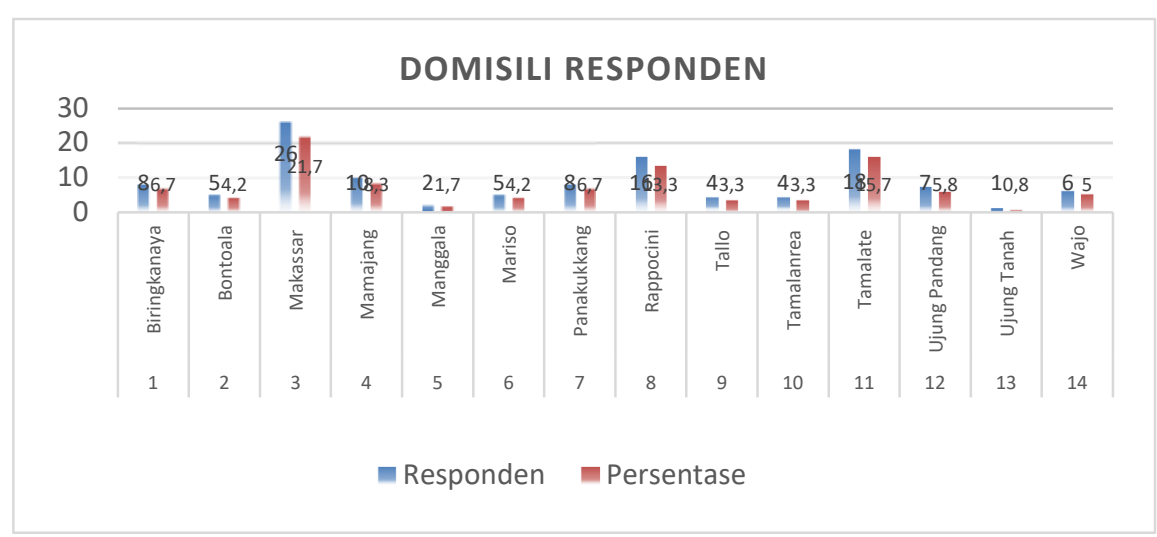

Gambar 2. Domisili Responden berdasarkan Kecamatan

Pertanyaan kuesioner berasal dari Kominfo Makassar tahun 2017 yang meliputi: Identitas diri responden (nama, jenis kelamin, nomor telepon, email, pendidikan, kecamatan domisili). Pertanyaan ditetapkan berdasarkan harapan pemerintah kota Makassar akan pengembangan dimensi "smart environment", yaitu mengembangkan program proteksi lingkungan (Protection). Pertanyaan terdiri dari: pengembangan sistem tata kelola, sistem tata kelola limbah industri, sistem tata kelola limbah dan sampah publik, menjaga keseimbangan ekosistem lingkungan, smart monitoring sampah, masyarakat peduli akan kebersihan, penukaran sampah dengan beras, penyelesaian masalah banjir, pemilahan sampah, armada mobil angkut, tim drainase, dan sampah permukaan laut [13]. 
Pengukuran menggunakan skala Likert [14], yaitu: skala yang digunakan untuk mengukur persepsi, sikap atau pendapat seseorang atau kelompok mengenai sebuah peristiwa atau fenomena sosial, berdasarkan definisi operasional yang telah ditetapkan oleh peneliti. Fokus penelitian menggunakan skala untuk mengukur persepsi responden terhadap rencana pengembangan tata kelola sampah menuju smart city berbasis greentech.

Hasil penelitian berdasarkan kuesioner yang dilakukan secara online dengan menggunakan aplikasi google form telah menunjukan bahwa terdapat 101 (84\%) responden menginginkan kota Makassar menjadi Smart Environment yang memiliki nilai Sombere untuk menuju Tata kelola Smart City dengan memberdayakan seluruh potensi sumberdaya yang ada.

\subsection{Paradigma Desain Prototype}

Desain Prototype ini terdiri dari 5 tahapan, yaitu:

\section{1) Communication}

Tahapan ini dilakukan dengan cara berkomunikasi kepada Dinas Kebersihan, Dinas Komunikasi dan Informasi, dan masyarakat pengguna layanan di kota Makassar. Hasil wawancara dan telah memperoleh gambaran mengenai tata kelola sampah. Menurut Deng Ical sapaan Syamsu Rizal selaku Pelaksana Tugas Wali Kota Makassar, dikatakan bahwa sampah di Makassar sudah mencapai 1,4 juta kilo per hari, sehingga harus ada kesadaran dari masyarakat terutama anak-anak untuk memahami suatu konsep dan slogan kalimat yaitu: "Kalau ada sampah lihat terus ambil". Istilah yang menjadi hangat ditelinga adalah LISA (LIhat Sampah Ambil).

Berikut keadaan rata-rata jenis sampah yang terbagi menjadi beberapa bagian, yaitu: sampah paper, glass, plastic, dan metal beserta desain dalam GIS.

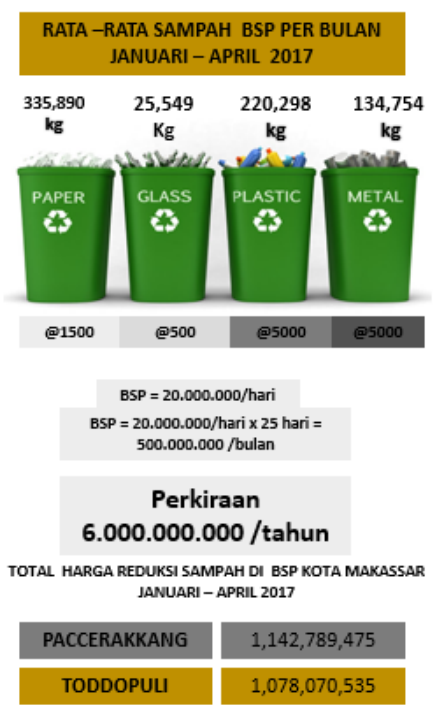

Gambar 3. Keadaan Sampah di Makassar

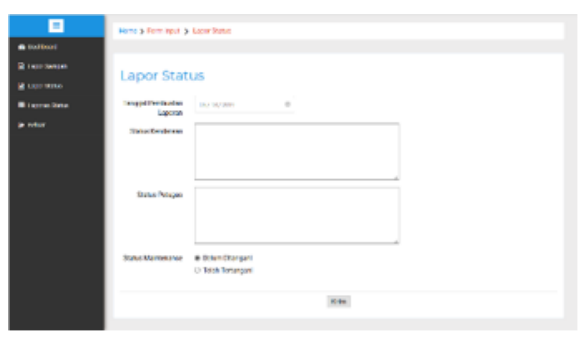

Gambar 4. GIS Status Pengisian Sampah

Keadaan Bank Sampah terdistribusi berdasarkan BSP (Bank Sampah Pusat), BSU (Bank Sampah Unit), BSS (Bank Sampah Sekolah).

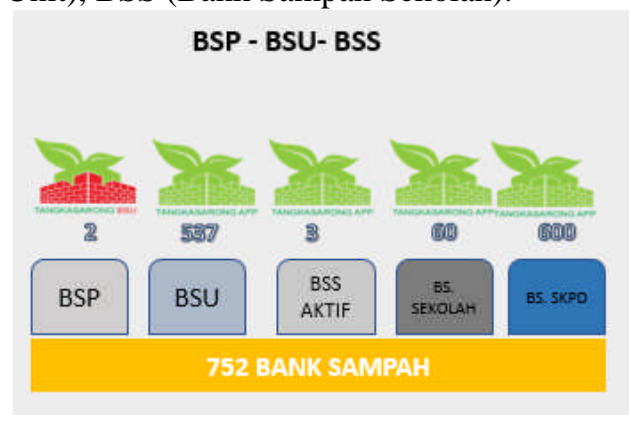

Gambar 5. Bank Sampah Kecamatan

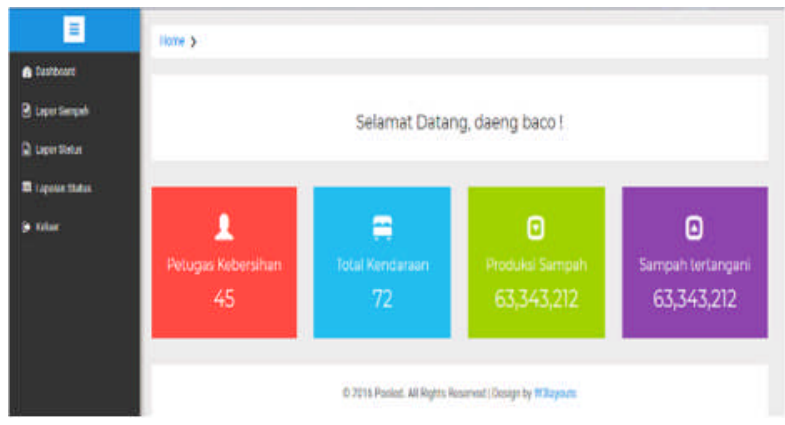

Gambar 6. GIS Petugas, Kendaraan, dan Sampah 
Disamping sampah dan pengelompokan berdasarkan Bank Sampah, terdapat pula kendaraan angkutan sampah yang berguna untuk mengambil dan mengantar sampak ke Tempat Pembuangan Akhir (TPA). Kendaraan tersebut terdiri dari kendaraan Truk, Hlux, Grand, dan Fukuda. Setiap kendaraan terdistribusi di setiap lokasi strategis seperti tingkat kecamatan atau bahkan kelurahan. Masyarakat sangat terbantu dengan adanya layanan sampah sehingga suasana bersih senantiasa terjaga. Lingkungan bersih dapat meningkatkan kesehatan masyarakat.

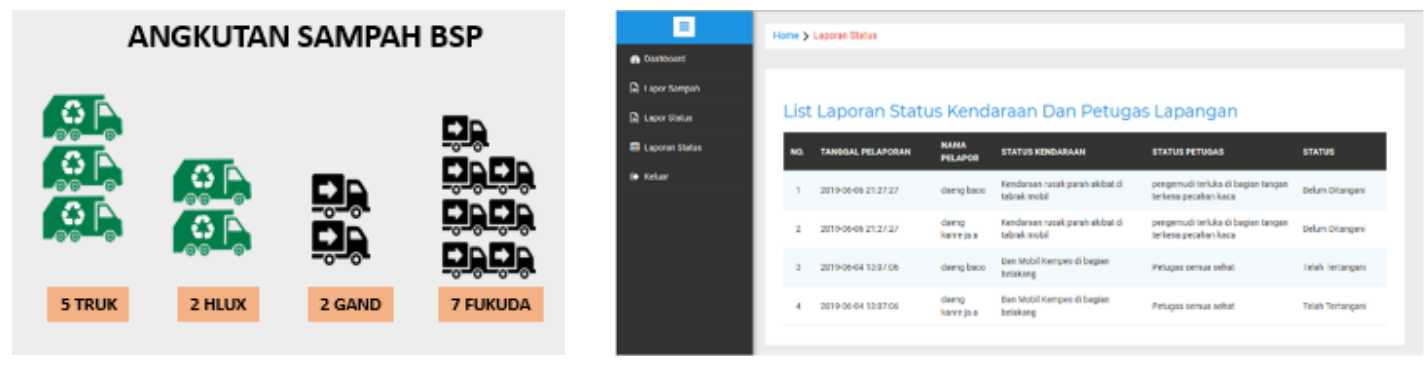

Gambar 7. Kendaraan Angkutan Sampah Gambar 8. GIS Petugas, Kendaraan, dan Sampah

Dengan tersedianya kendaraan akan memudahkan untuk mengetahui jenis dan lokasi sampah yang akan dikelola. Melalui ketersediaan anggaran akan dapat diciptakan sistem persebaran sampah dan tempat pengumpulan sampah di kecamatan sebelum dibawa ke tempat pembuatan akhir sampah di Antang.

\section{2) Quick Plan}

Setelah memperoleh informasi yang diperlukan, tahapan berikut adalah melakukan perencanaan secara cepat berdasarkan kebutuhan pengguna dan masyarakat pada umumnya. Untuk memudahkan dalam perencanaan dibutuhkan proyeksi sampah berdasarkan jenis sampah. Perencanaan ini melibatkan para pemangku kepentingan seperti Dinas Kebersihan, Dinas Komunikasi dan Informasi, dan masyarakat.

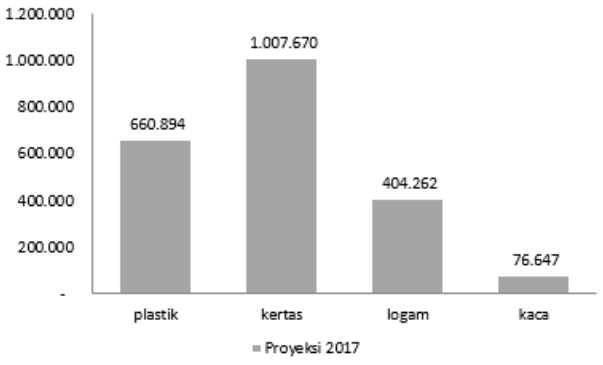

Gambar 9. Proyeksi Jenis Sampah

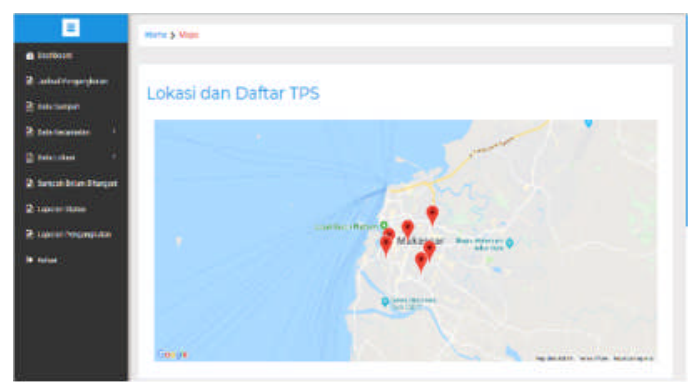

Gambar 10. Lokasi Sampah di Kecamatan

Untuk dapat mendesain tata kelola sampah dibutuhkan informasi mengenai keadaan dan jenis sampah. Berdasarkan informasi dari Dinas Kominfo Kota Makassar diperoleh proyeksi sampah tahun 2017, yaitu: plastik 660.894 ton, kertas 1.007.670 ton, logam 404.262 ton, dan kaca 76.647 ton. Hasil proyeksi ini berguna dalam menyusun sistem tata kelola sampah yang dibangun untuk kemudahan dalam monitoring dan evaluasi.

Perencanaan dilakukan melalui pertemuan dan konsultasi kepada ahli yang ada seperti mendatangkan ahli dari PUM Netherlands Senior Experts. Pada bulan Januari 2019 Universitas Atma Jaya Makassar telah mendatangkan Mr. Albrecht Bresters untuk bertemu dengan Walikota Makassar Ir. H. Ramdham Pomanto pada Senin, 11 Februari 2019. Hasil pertemuan telah ada pemikiran dan pengembangan konsep tata kelola sampah untuk dapat diterapkan di Makassar.

\section{3) Modeling Quick Design}

Setelah mendengar dan mendapat masukan dari para pemangku kepentingan, kemudian dibuat model desain secara cepat. Desain ini meliputi aplikasi web, aplikasi android, dan website pengelola jenis sampah. Desain didasarkan pada kebutuhan berbagai pihak yang terkait seperti masyarakat, pembeli dan pengrajin. Pemerintah yang sebagai regulator dan pemberi layanan, mempersiapkan dengan baik layanan dalam bentuk sistem yang terintegrasi agar dapat memudahkan untuk diakses secara luas. 


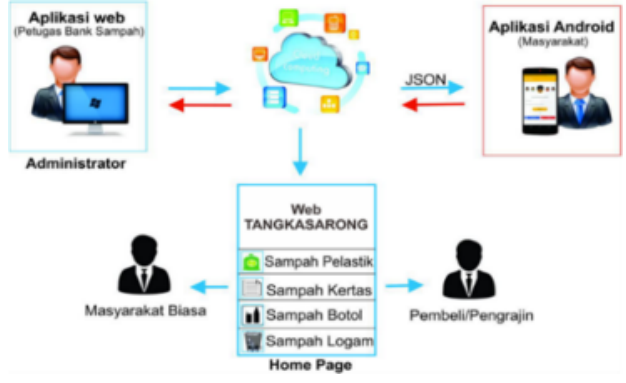

Gambar 11. Desain Tata Kelola Sampah

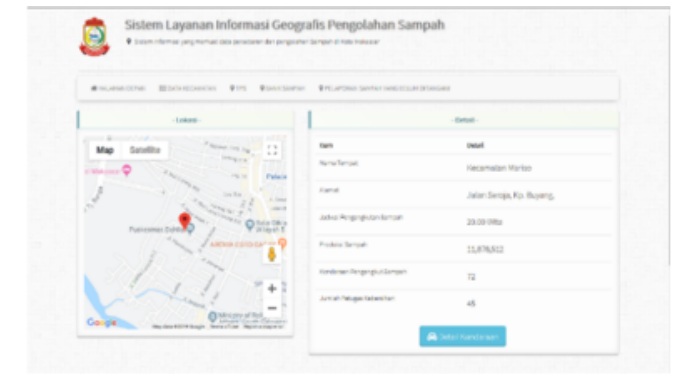

Gambar 12. Prototype GIS Pengolahan Sampah

\section{4) Construction of Prototype}

Sebuah Aplikasi Bank Sampah berguna untuk mendukung pengembangan bisnis kreatif, memudahkan masyarakat menukar sampah, mengelola transaksi sampah, monitoring informasi sampah kota dan informasi produk kerajinan dan transaksi lainnya serta dilengkapi sistem android dan web portal. Aplikasi yang didesain bernama Aplikasi Pengelolaan Sampah menuju smart city. Di masa mendatang aplikasi ini bisa memberikan ide dan gagasan untuk pengembangan ke arah berbasis Green Technology yang mampu mengintegrasikan sistem lain di Makassar seperti smart government (pemerintahan cerdas), smart economy (ekonomi cerdas), smart society (kehidupan sosial cerdas), smart mobility (mobilitas cerdas), smart environment (lingkungan cerdas). Ketersediaan penyimpanan data dan perangkat perangkat keras secara permanen akan dapat ikut mendukung terselenggaranya tata kelola sampah.

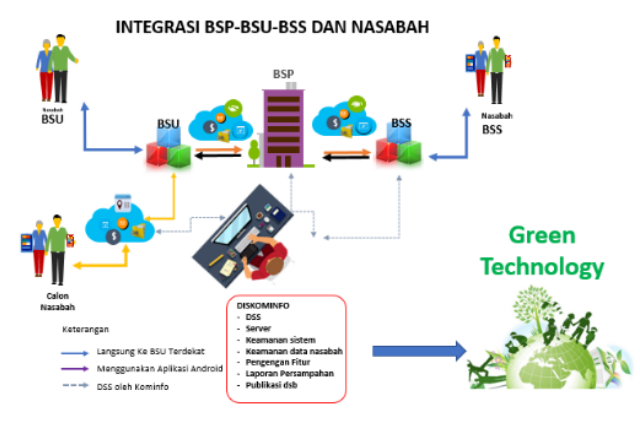

Gambar 13. Integrasi Bank Sampah

Memperhatikan dalam UU 32 tahun 2009 tentang Perlindungan dan Pengelolaan Lingkungan Hidup (PPLH) yang merupakan kesatuan ruang dengan semua benda, daya, keadaan dan makhluk hidup, termasuk manusia dan perilakunya yang mempengaruhi alam itu sendiri, kelangsungan kehidupan dan kesejahteraan manusia serta makhluk hidup lain [15].

Pemerintah memberlakukan prinsip melalui UU Pengelolaan Sampah Nomor 18 Tahun 2008 dan Peraturan Menteri Dalam Negeri Nomor 33 tahun 2010 tentang Pedoman Pengelolaan Sampah dimana di dalamnya diatur proses pengelolaan sampah dari hulu hingga ke hilir atau dari mulai timbunan sampah di tempat-tempat umum, usaha, industri maupun tingkat sekitar rumah tangga. Untuk itu perlu upaya secara serius dan berkelanjutan dalam melakukan tata kelola sampah agar masyarakat dapat hidup dengan sehat, baik, dan nyaman untuk menjaga kelangsungan hidup kita dan kesejahteraan.

\section{5) Deployment Delivery and Feedback}

Untuk dapat mengetahui efektifitas dalam pembuatan sistem maka perlu mendapat tanggapan dari pengguna sistem. Hasil desain perlu mendapat masukan dari para pemangku kepentingan agar dapat dikembangkan di masa mendatang sesuai dengan harapan dan kebutuhan.

\section{Kesimpulan}

Hasil penelitian telah menunjukkan bahwa konsep tata kelola smart city dapat diterapkan karena mendapat respon yang baik dari masyarakat. Desain model prototype dapat dibuat untuk membantu serta memberikan kontribusi nyata kepada pemerintah kota dan masyarakat Makassar dalam melakukan tata kelola sampah menuju smart city berbasis green technology. 


\section{Saran}

Penelitian lanjutan dapat menambahkan kriteria dan karakter terhadap 6 (enam) dimensi utama yaitu: smart government (pemerintahan cerdas), smart economy (ekonomi cerdas), smart society (kehidupan sosial cerdas), smart mobility (mobilitas cerdas), smart environment (lingkungan cerdas), dan quality of live (hidup berkualitas) secara terintegrasi.

\section{Ucapan Terima Kasih}

Penulis mengucapkan terima kasih kepada pemerintah kota makassar, Direktorat Riset dan Pengabdian Masyarakat (DRPM), Lembaga Layanan Pendidikan Tinggi Wilayah IX (LL Dikti IX), Dinas Kementerian Komunikasi dan Informasi, dan Dinas Lingkungan Hidup dan Kebersihan yang telah memberi dukungan dan bantuan terhadap pelaksanaan penelitian ini.

\section{Daftar Pustaka}

[1] Kementerian Komunikasi dan Informasi. 2017. Langkah Menuju 100 Smart City. Jakarta.

[2] Direktur Perkotaan dan Perdesaan. Kementerian PPN/ Bappenas. Konferensi e-Indonesia Initiative (eII) dan Smart Indonesia Initiatives (SII) Forum ke-1. 15 Oktober 2015. Bandung.

[3] Khaedar. 2016. Implementasi Program Makassar Tidak Rantasa (MTR) Di Kecamatan Tamalate Kota Makassar. UNM. Makassar.

[4] Pallawa, Maharani, Irwan. 2014. Analisis Pelaksanaan Program Gerakan Makassar Ta' Tidak Rantasa di Kota Makassar. Jurnal Ilmu Pemerintahan Volume 7 Nomor 1 Januari 2014. 63-74. ISSN: 1979-5645.

[5] Van Grembergen, Wim; Steven De Haes. 2009. Moving From IT Governance to Enterprise Governance of IT. ISACA Jurnal.

[6] Chandra. 2016. Strategi Pembangunan Smart City dan Tantangannya bagi Masyarakat Kota. Jurnal Strategi dan Bisnis Vol. 4, No. 2.

[7] Widyaningsih. 2013. Kajian Pemakai Website Jakarta Smart City Terhadap Kepercayaan Masyarakat Pada Pemerintah Provinsi DKI Jakarta. Jakarta.

[8] Cohen, Boyd. 2011. Basic Smart city Indicators: Smart city Wheel.

[9] Alberti, Elisa. 2011. Smart Mobility Vision Report, Deliverable of the Project Smart Metropolitan Areas Realised Through Innovation and People. European Commision.

[10] Utomo, CEW., Hariadi, M. 2016. Strategi Pembangunan Smart City dan Tantangannya bagi Masyarakat Kota. Jurnal Strategi dan Bisnis Volume 4 Nomor 2, Oktober 2016. Surabaya.

[11] Roger, S. Pressman. 2012. Rekayasa Perangkat Lunak (Pendekatan Praktisi) Edisi 7: Buku 1. Yogyakarta: Andi

[12] Prakasita, Nugroho. 2018. Perancangan Sistem Informasi Akunansi Penjualan Dan Persediaan Di Central Steak and Coffee Boyolali. Jurnal Nominal Volume VII Nomor 1.

[13] Kominfo Makassar. Pengelolaan Data Smart City. Makassar. 2017.

[14] Djaali. 2008. Skala Likert. Jakarta: Pustaka Utama.

[15] Menteri Lingkungan Hidup dan Kehutanan. 2009. UU Nomor 32 Tahun 2009 tentang Perlindungan dan Pengelolaan Lingkungan Hidup (PPLH). 